\title{
SUMMARY OF SCAN SITE 5
}

\author{
G. W. Moore, U. S. Geological Survey, La Jolla, California \\ and \\ G. F. Sharman, Scripps Institution of Oceanography, La Jolla, California
}

\section{OBJECTIVE OF DRILL HOLE}

The revised location for Site 5 is latitude $40^{\circ} 02^{\prime} \mathrm{N}$, longitude $130^{\circ} 06^{\prime} \mathrm{W}$; and, the water depth is 3290 meters. Positioned between Sites 4 and 6 along a line that has become a North Pacific type section for seafloor magnetic stratigraphy, this site will add an important third point to make a curve out of the straight-line stratigraphic sequence that Sites 4 and 6 alone would define. An abrupt increase in sediment thickness between Sites 4 and 5, discovered during this survey, suggests that the Gorda Rise began as a new line of sea-floor spreading on considerably older terrain. Site 5 is in a good place to study this possible unconformity and, hopefully, to define its relationship to the tectonic history of western North America. Surface sediment at Site 5 is a Pleistocene deep-sea ooze. Tracing this rich fossil record to depth is an additional, important objective of coring at the site.

\section{SURVEY METHODS}

The survey of this site was made from the Argo between March 16-18, 1969. Navigation was by Loran A, with a fix precision of approximately 2 kilometers. Magneticintensity traverses and acoustic-reflection profiles at $12,3.5$ and $0.1 \mathrm{kHz}$ were run on a grid 75 kilometers square, with tracks about 20 kilometers apart. On the accompanying subbottom profiles, a 10-second sweep was used, and the spacing between hour marks is about 20 kilometers. Near this site, a piston core was taken, the bottom was photographed, and the heat flow was measured.

\section{NATURE OF SITE}

The original position for Site 5 , at $40^{\circ} 50^{\prime} \mathrm{N}, 130^{\circ} 20^{\prime} \mathrm{W}$, lies on top of a seamount with a minimum depth of approximately 900 meters. This seamount, and a system of dikes and flows that radiate from it, are younger than the terrain sampled by this drill hole. The new position for the site is satisfactory, however, and the sediment is 110 meters thick. The heat flow is about average at $1.3 \mu \mathrm{cal} / \mathrm{cm}^{2} \mathrm{sec}$.

\section{MICROPALEONTOLOGY}

David Bukry

U. S. Geological Survey, La Jolla

\section{General Comments}

Samples taken at 1.5 -meter intervals from the piston cores, recovered during the preliminary surveys of the proposed Deep Sea Drilling Project sites in the northeast Pacific, have been examined for calcareous nannofossils. The identified assemblages of nannofossils indicate that Pliocene sediment containing discoasters is present in the upper 10 meters at only one place, Site 6 . Elsewhere, only Pleistocene assemblages are present in the upper 10 meters. The abundant, widely distributed Holocene nannofossil, Emiliania huxleyi (Lohmann) is not represented in any of the samples examined.

Diatoms are common only in surface samples (0 to 1 centimeter) at Sites 1,2 and 4 . Foraminifera are sparsely present in several samples from Sites 1, 2, 4, 5 and 6.

\section{SCAN-5-P}

Core length: 8.9 meters. Pleistocene calcareous nannofossil assemblages are present throughout this core. Moreover, the nannofossils compose the bulk of the sediment, which consequently is a nannofossil ooze. A sample at 24 to 25 centimeters contains a unique assemblage extremely rich in Coccolithus pelagicus and Gephyrocapsa oceanica. Assemblages are more diverse in samples from the lower part of the core: C. pelagicus, Cyclococcolithus cricotus Gartner, G. oceanica, Helicopontosphaera kamptneri Hay and Mohler, Rhabdosphaera clavigera Murray and Blackman, and $R$. stylifera Lohmann. 


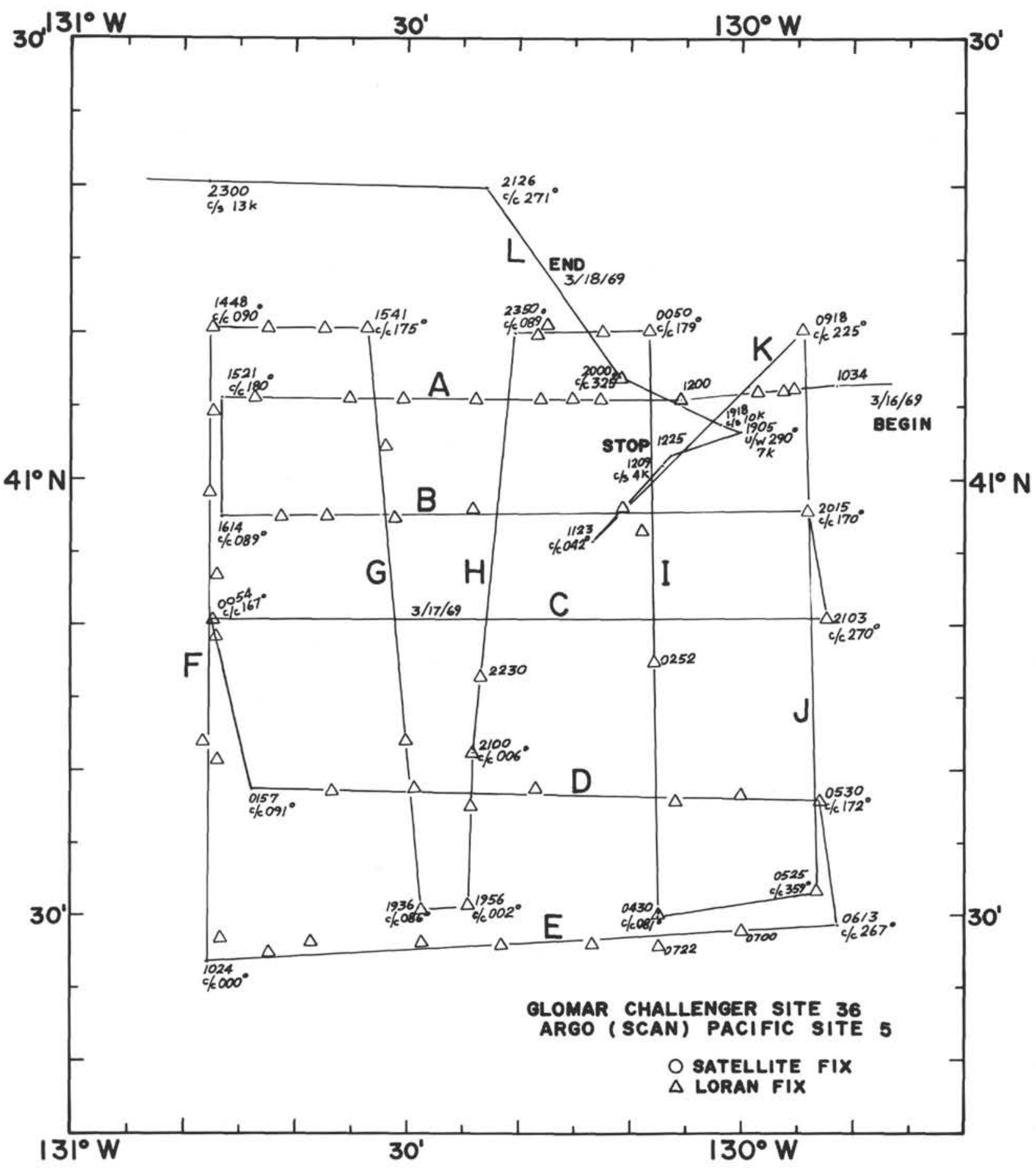



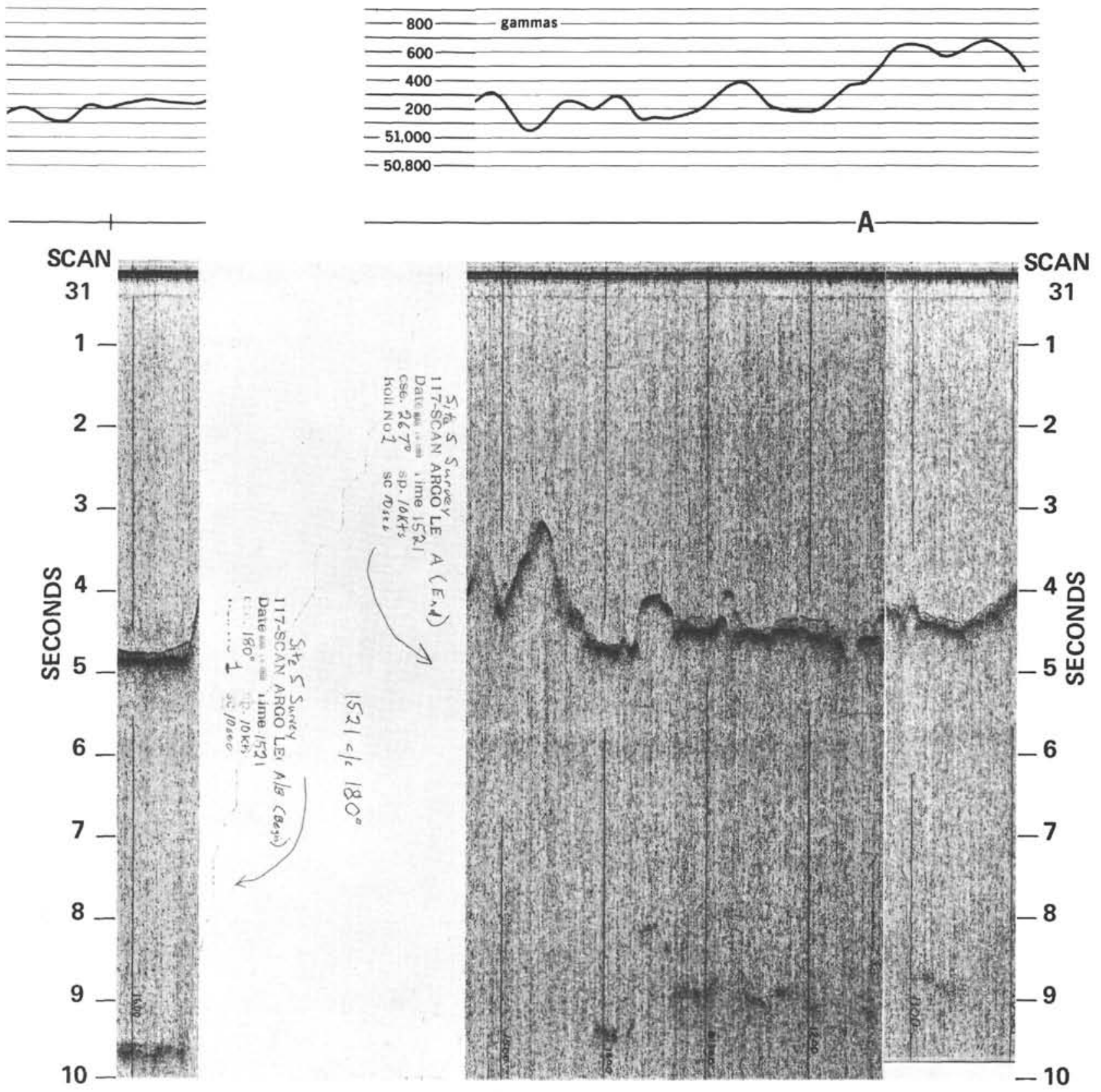

SCAN Survey, Site 5, Track A. 

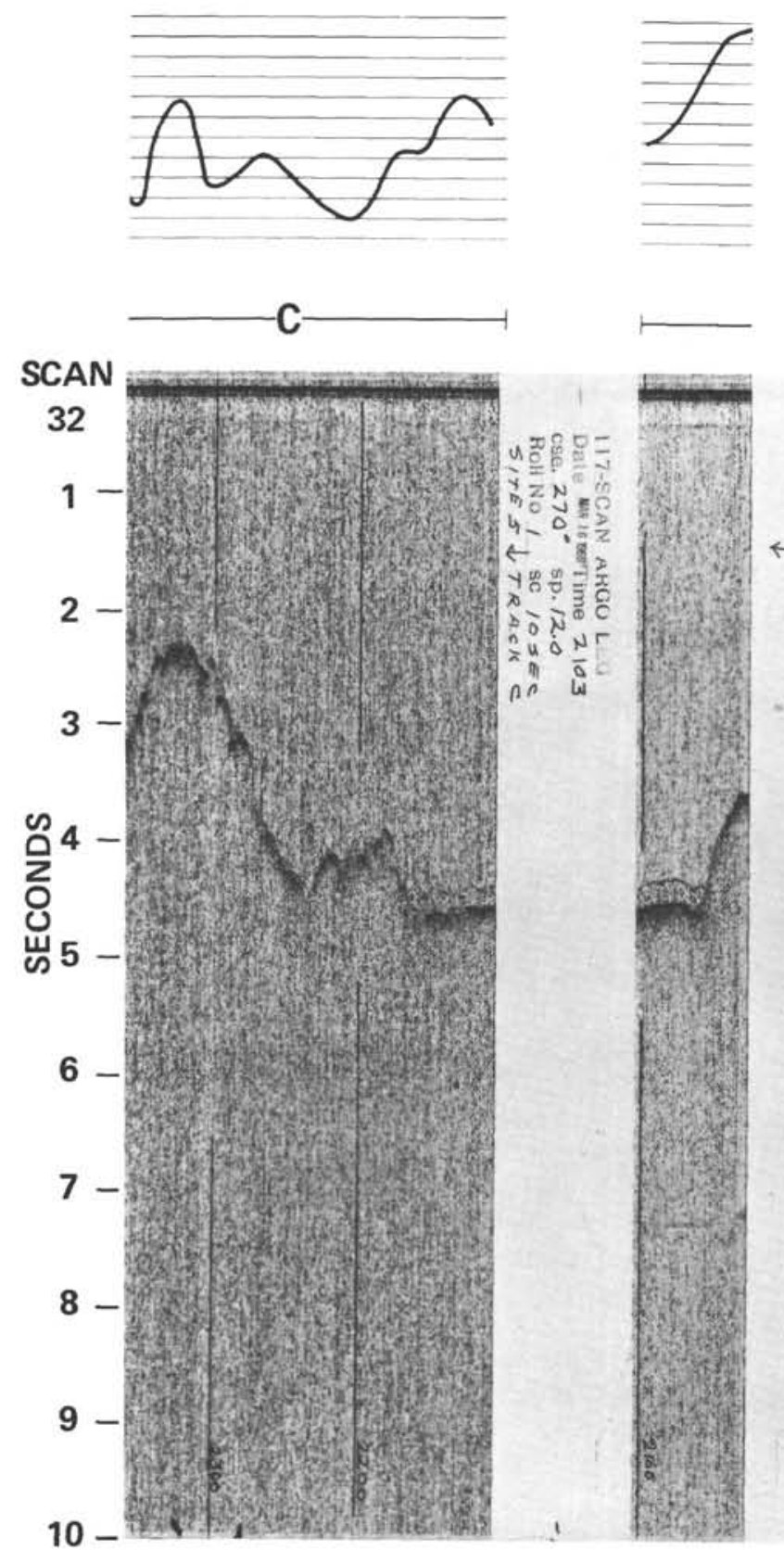
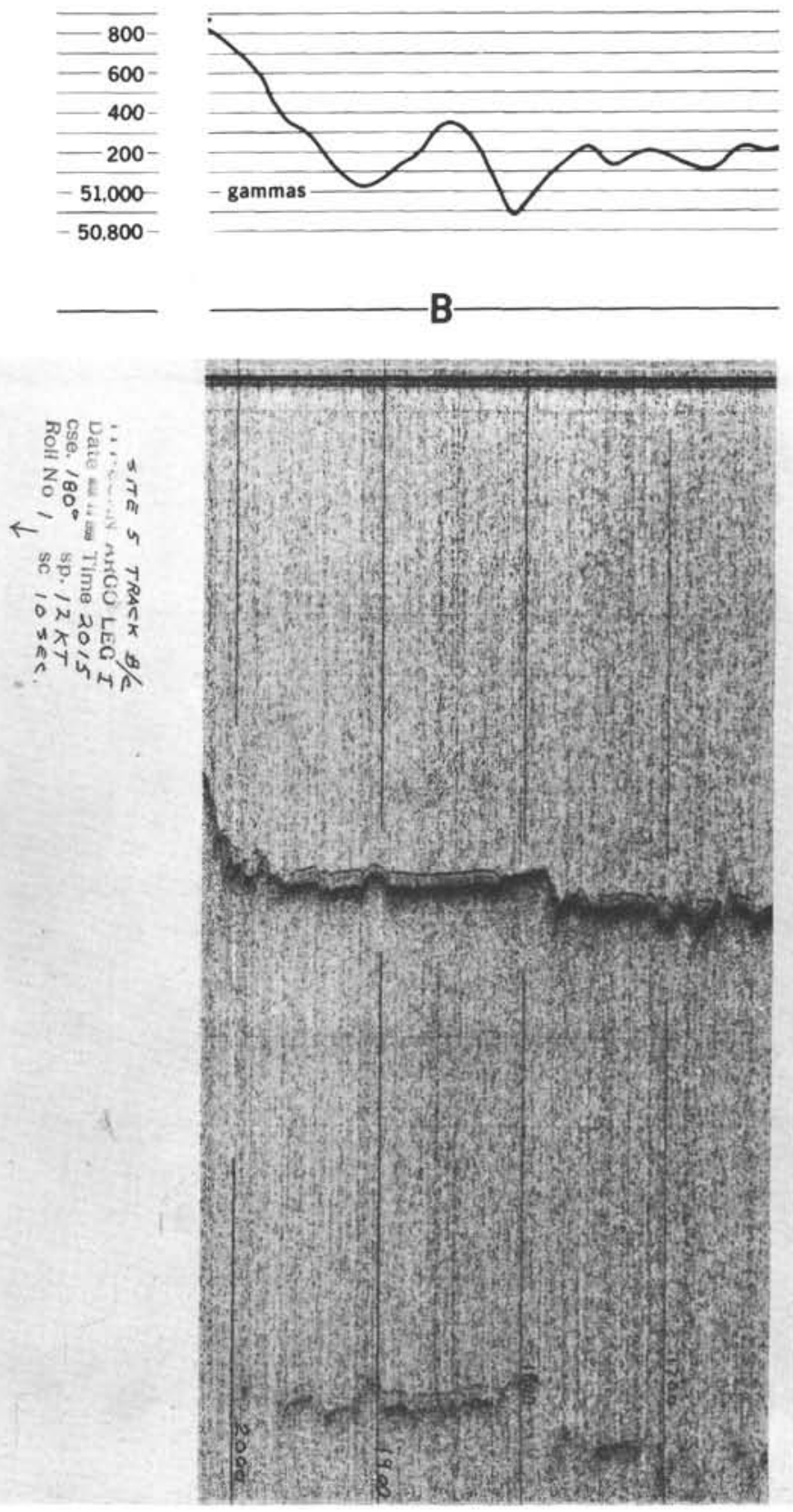

SCAN

32

$-1$

$-2$

$-3$

-4 号
-5 岁

$-6$

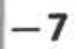

$-8$

$-9$

$-10$

SCAN Survey, Site 5, Tracks B and C. 

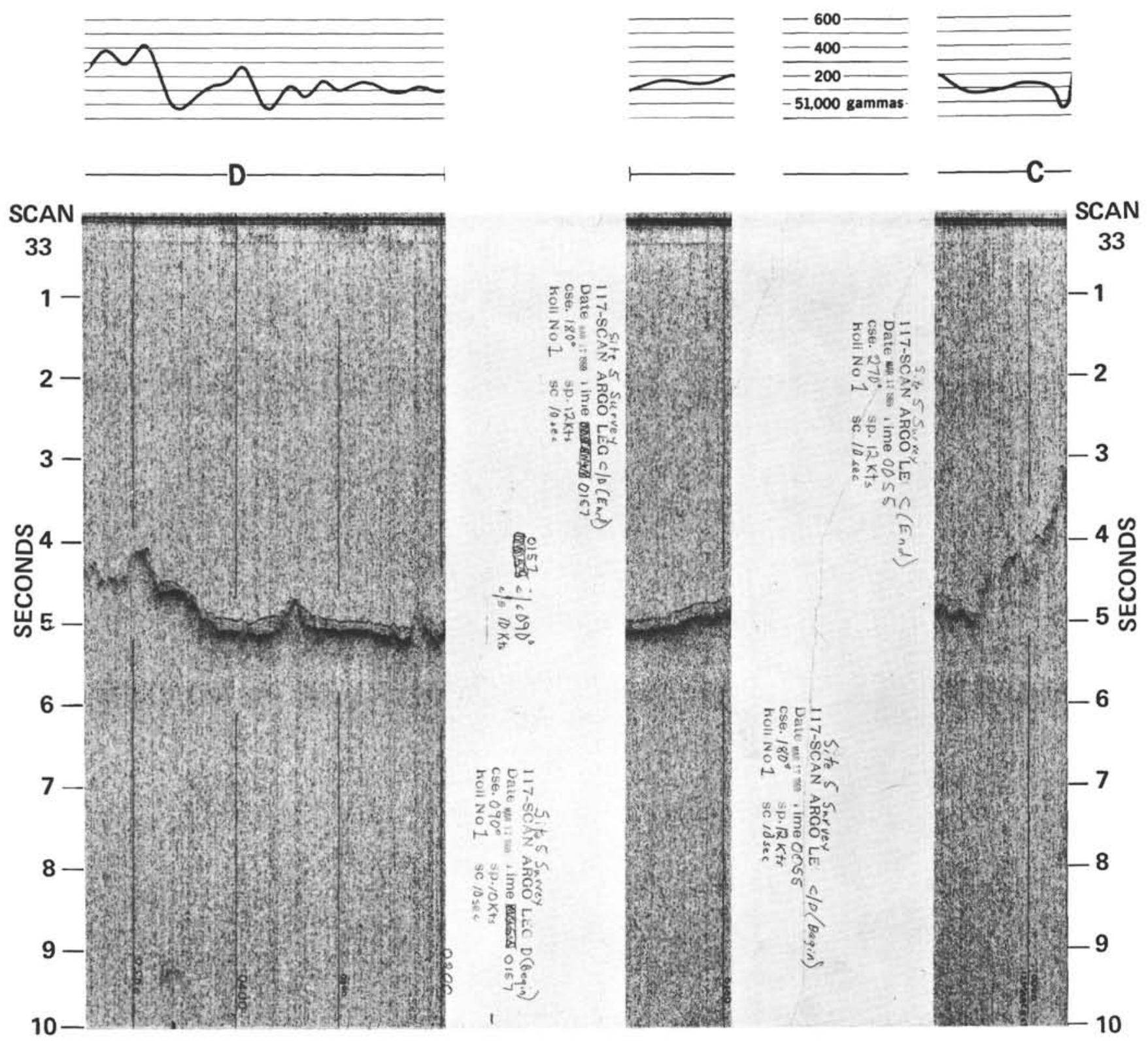

SCAN Survey, Site 5, Tracks C and D. 

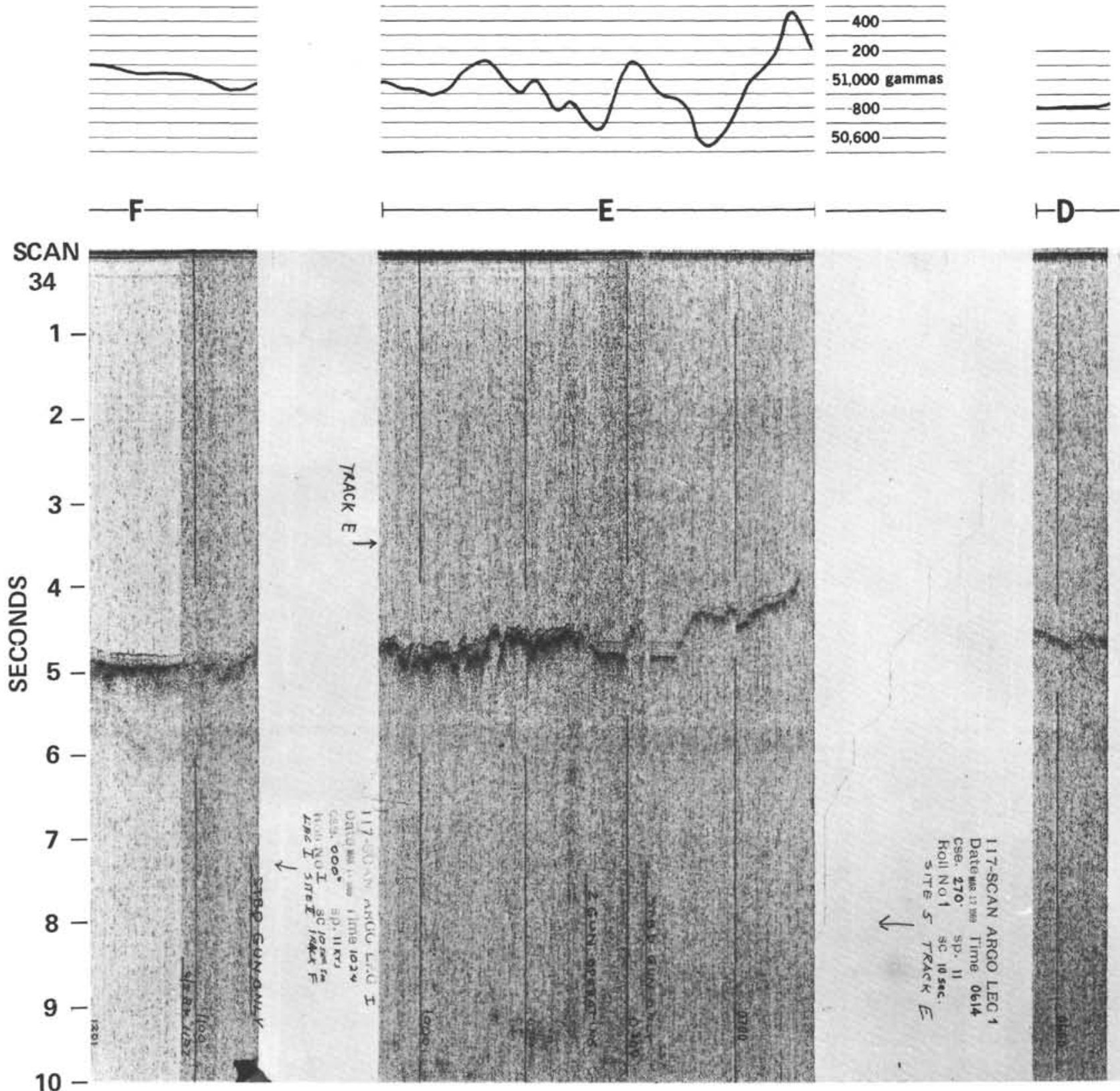

$-2$

$-3$

-4 号
导
-5 岁

$-6$

$-7$

$-8$

$-9$

$-10$

SCAN Survey, Site 5, Tracks D, E and F. 

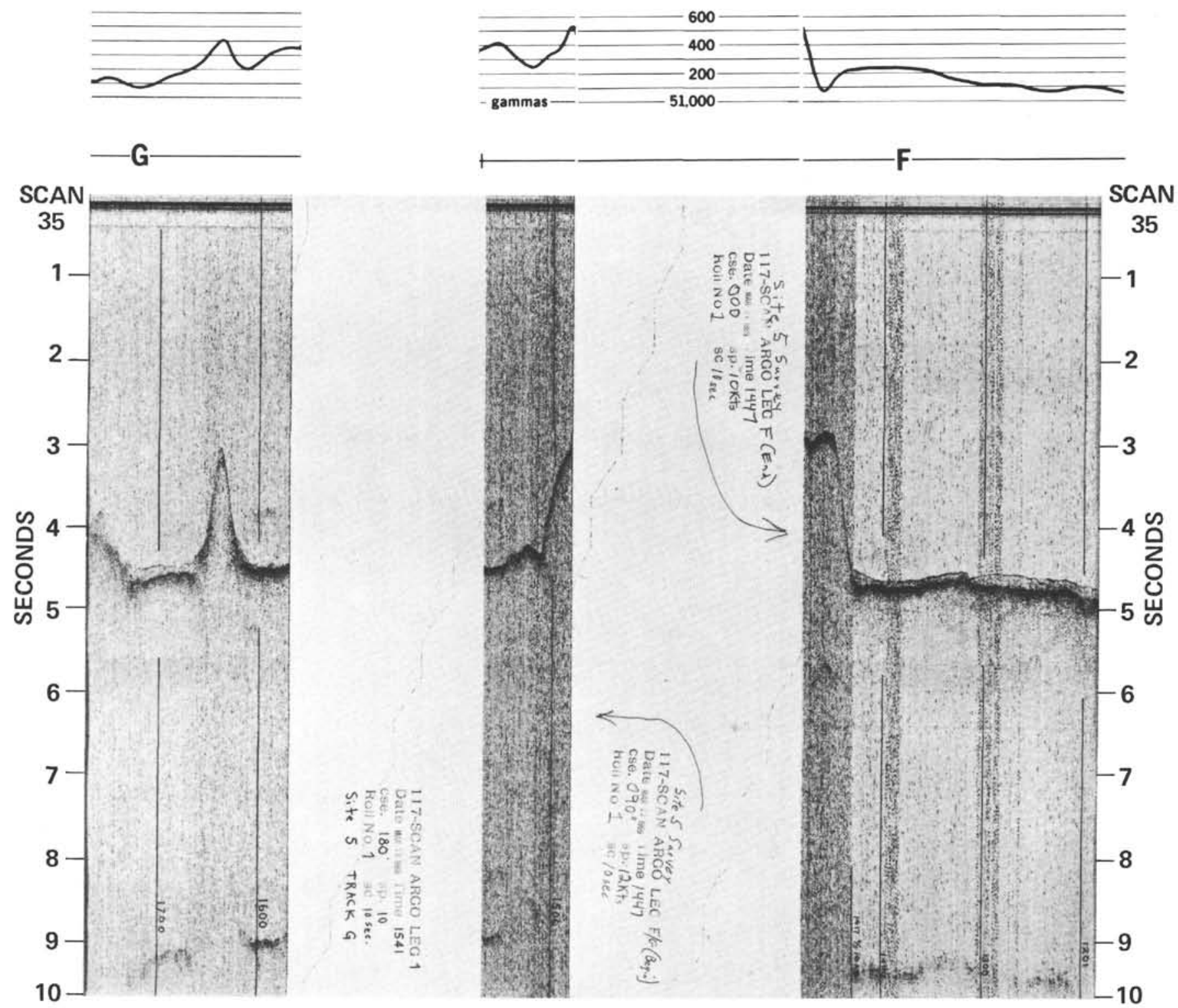

SCAN Survey, Site 5, Tracks $F$ and G. 

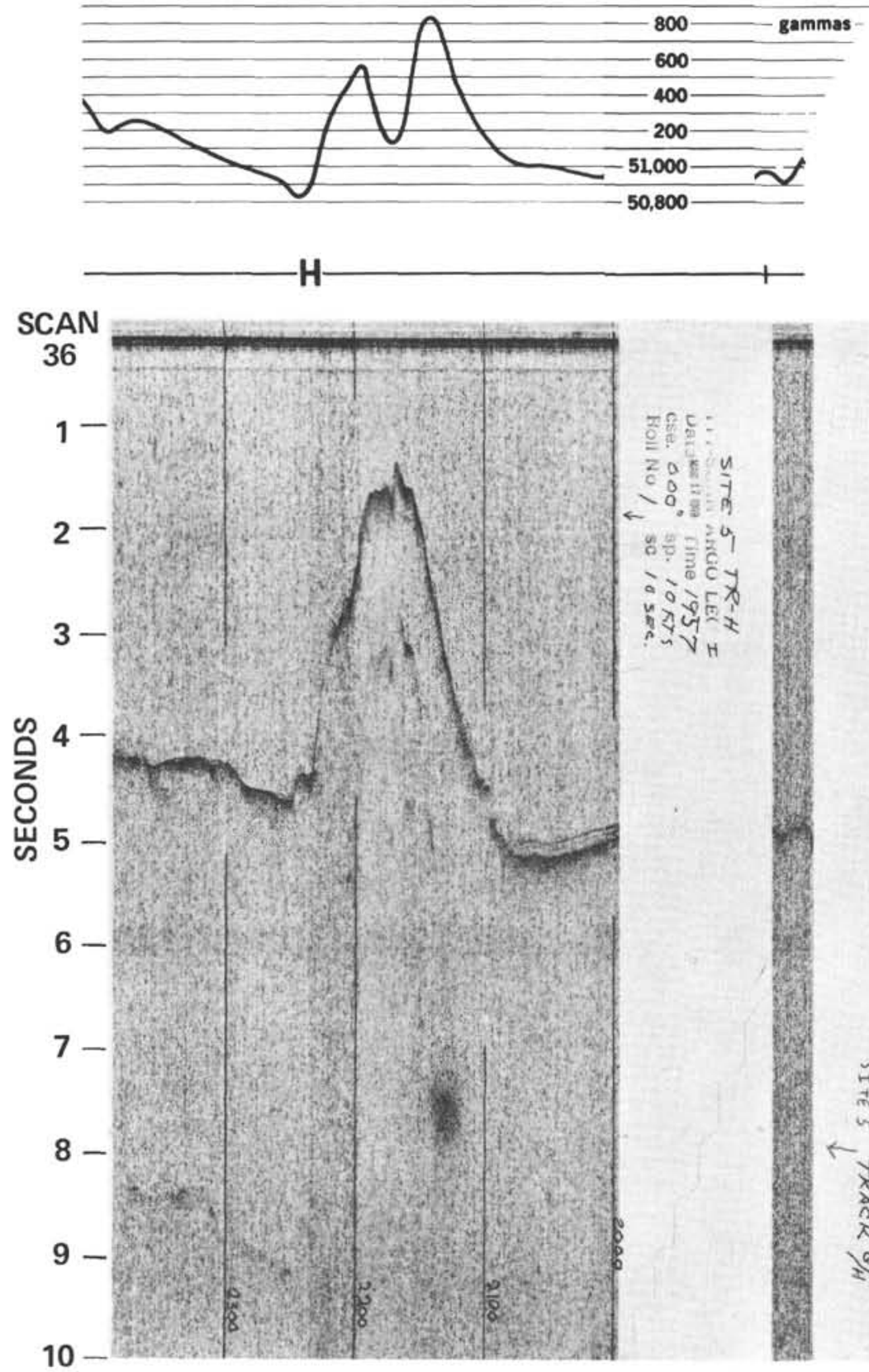
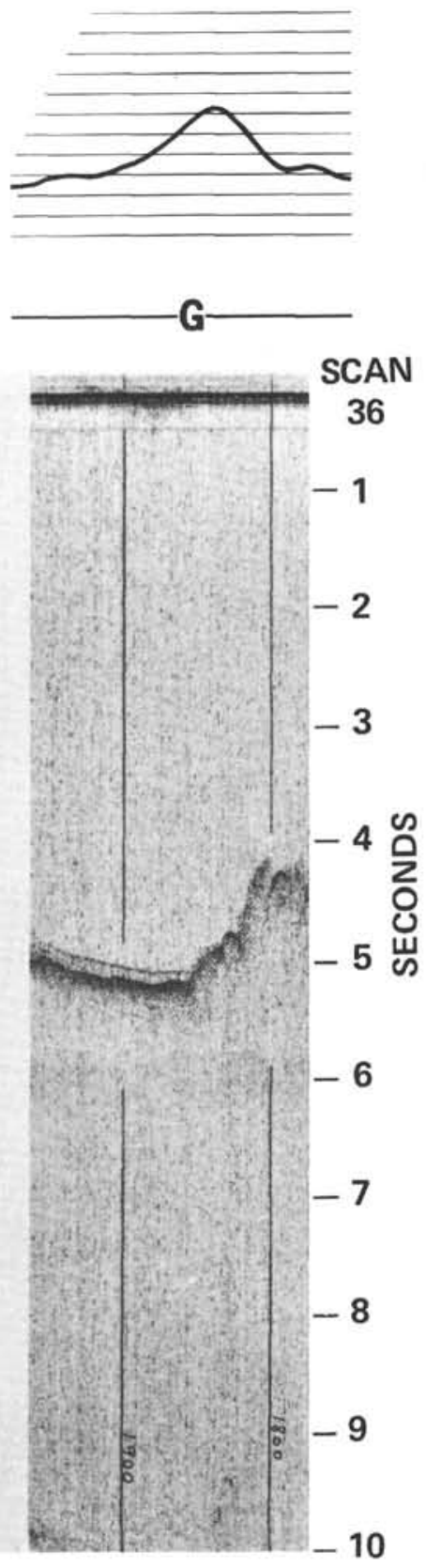

SCAN Survey, Site 5, Tracks $G$ and $H$. 

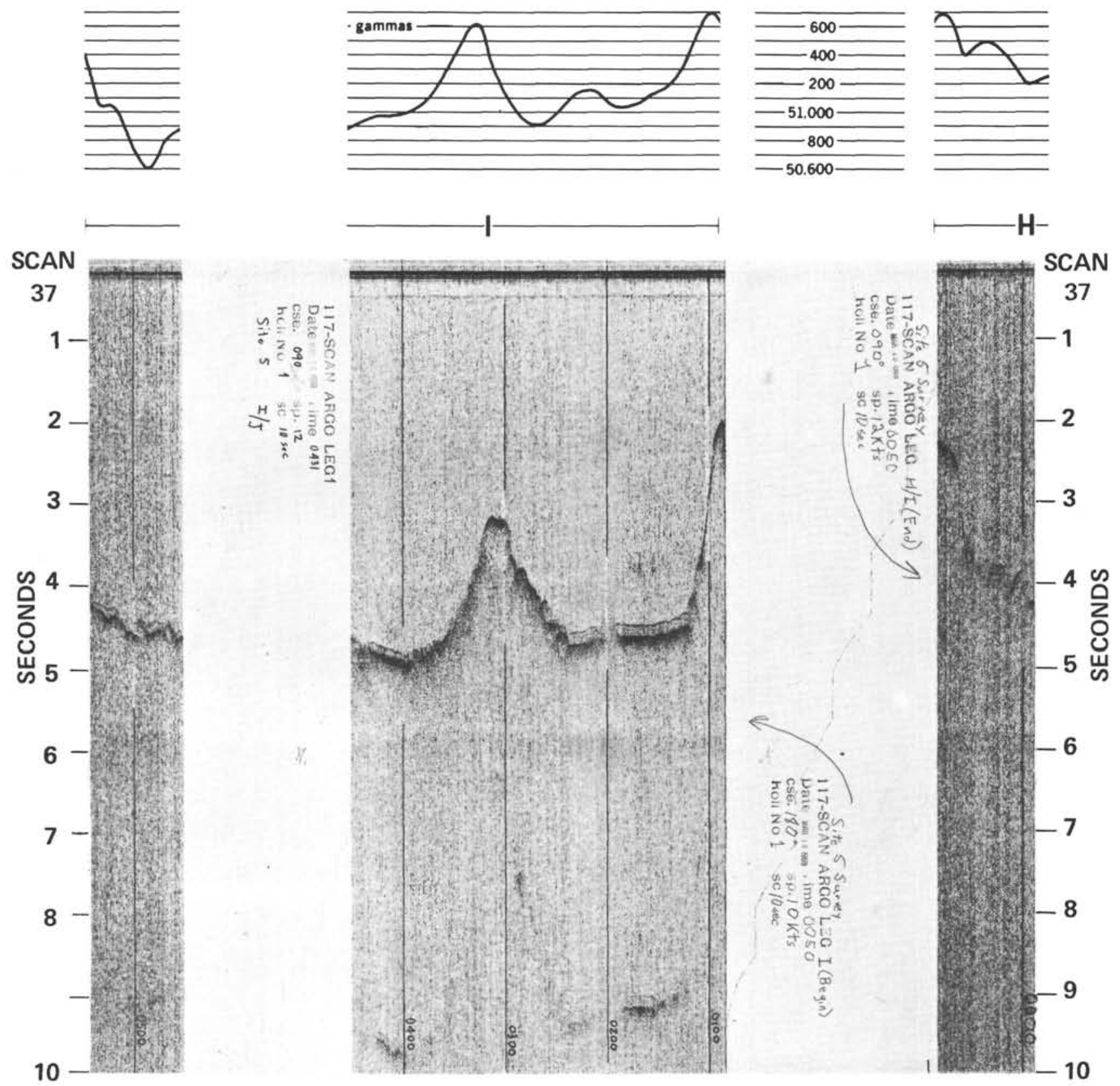

SCAN Survey, Site 5, Tracks $H$ and I. 

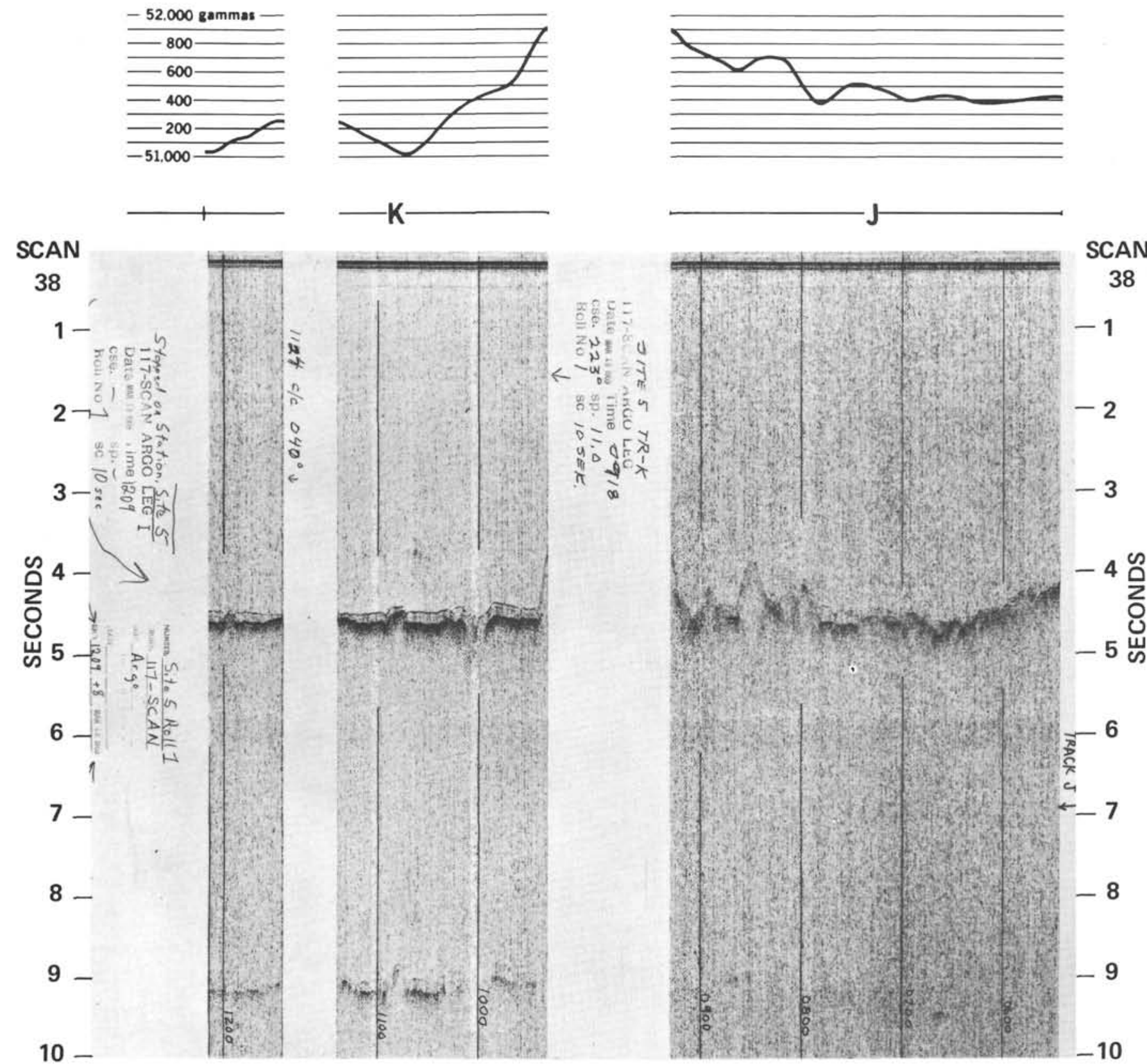

SCAN Survey, Site 5, Tracks $J$ and $K$. 

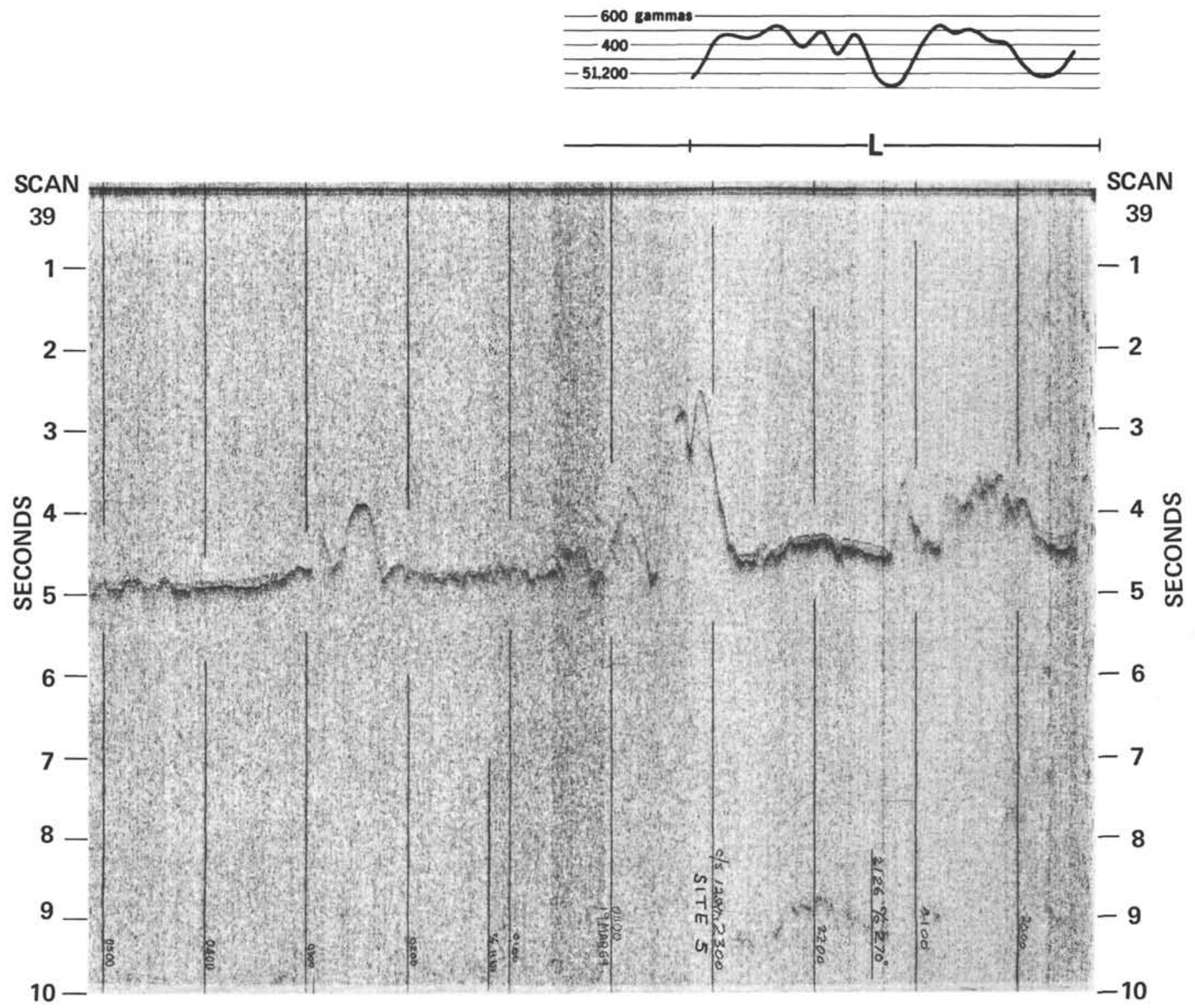

SCAN Survey, Site 5, Track L. 


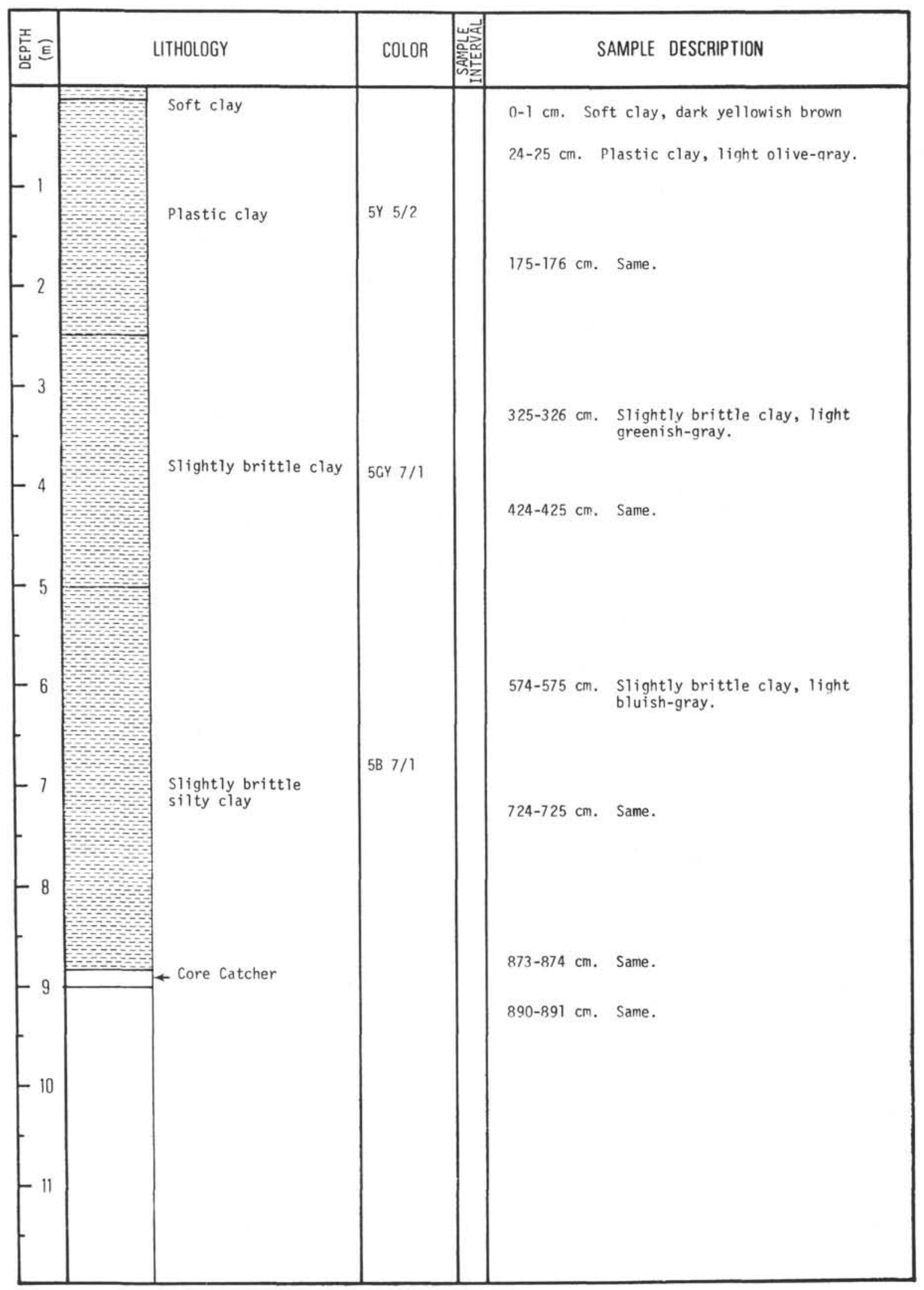

Summary of Piston Core 5. 